\title{
Mapping the Past, Present, and Future of Teaching Leadership Chairs in Canada: A Report
}

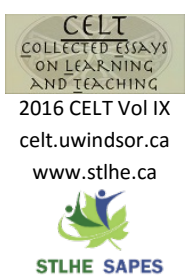

\author{
David M. Andrews, Judy A. K. Bornais, and Ken M. Cramer \\ University of Windsor
}

We explore the advent and initiatives of teaching leadership chairs - modeled after the Canada Research Chair framework - to instill individuals or small groups of teaching leaders at various centres across the country to stimulate educational change. In its past, present, and future, we explore the grassroots of teaching leadership chairs and their spread nationwide; outline the current situation of initiatives and challenges we have experienced at our institution; and conclude with some new avenues for teaching leadership via campus-wide joint projects.

\section{Introduction}

$\mathrm{T}$ eaching Leadership Chairs (TLCs) are a relatively new phenomenon in Canada, but have been gaining momentum across university campuses in the last decade. An investigation of Canadian universities in 2011-2012 revealed that fifteen had a Teaching Chair or Teaching Chair program (Eansor, 2012), seven of which were in Ontario alone (Wright et al., 2012). Since 2015, five institutions have ushered in new Teaching Chair programs. Conversely, it should be noted that in this timeframe, there was also a suspension of one existing Teaching Chair program at Queen's University (2012). Similar to the Canada Research Chairs Program that encourages specialization and mobilization through essential research initiatives nationwide, TLCs focus on teaching and learning initiatives and activities that impact student learning on the local, national, and international stages. In 2011, as part of the Student Advocacy Conference Meeting Brief, the Ontario University Student Association argued for the establishment of five TLCs at each Ontario university funded by the Ontario Provincial Government (OUSA, 2011). Both the Higher Education Quality Council of Ontario (HEQCO) and the Council of
Ontario Universities (COU) have advocated for Teaching Chair positions as a strategy to improve student learning in colleges and universities in Ontario.

Most newly appointed chairs outline how they will accomplish a series of goals, disseminate their results to the wider community, and impact the scope of teaching and learning both in the short and long terms. Arguably, TLC terms are quite variable across Canada, and are reflective of the funding available. Some chairs are funded for a single year, with others funded across a multi-year term (the latter system being far more common across Canadian institutions).

Currently there is no provincial or national strategy for funding TLCs that models the CIHR Canada Research Chairs Program. While understanding the historical context of TLCs is important, this report will outline the historical context and discuss the process, successes, and challenges of implementing the TLC program at the University of Windsor. In addition, we will share outcomes and experiences from our May 2015 symposium (put on jointly by our institution and Oakland University, MI), and the insights and revelations uncovered during our STLHE 2015 round-table session. Lastly, we present several 
changes in future teaching practices and policies that are currently under consideration by the TLCs at Windsor.

\section{Reviewing Our Past}

The concept of implementing a Teaching Leadership Chair program at the University of Windsor was initiated by Professor Donna Marie Eansor (Faculty of Law) in discussions with Dr. Alan Wright (Vice Provost Teaching and Learning). The initiative was brought forth to the 2012 Provost's Committee on Teaching and Learning, who sought strategic funding to implement the program. Inception of the program began in January 2014 with seven chairs - one for each faculty, except Law (represented by Eansor, Chair of the TLC Council). Base funding was approved for four TLCs, which would continue as three-year appointments. The individual projects introduced by the seven TLCs are diverse and varied, consisting of (but not limited to): experiential learning projects including student teaching and outreach in Tanzania; the implementation of a peer collaboration network designed to provide faculty with opportunities for professional development through peer observation of teaching; an examination of how research and teaching are linked and influence each other over the course of a career; successful implementation of an international summer institute for faculty development (chiefly from China); creation of on-line learning modules designed to aid student success in transitioning to university; assurance of learning and curriculum evaluation in business; flipping the engineering classroom; and an initiative to promote experiential, active, researchbased learning in the Faculty of Science.

\section{Unwrapping Our Present}

At the University of Windsor, the TLC Council meets regularly to ensure the ongoing achievement of each TLC's goals. However, it was clear that broader networking and greater national and international outreach were vital. In particular, three steps were taken to entrench the TLC goals into a wider context: (1) an international symposium, (2) a national conference on teaching and learning, and (3) directed collaborative efforts.

To begin, the TLC Council at Windsor organized an international symposium in May 2015 to invite regional TLCs and other institutional delegates (viz. faculty, administrators, students, and educational developers) to a round-table forum, to outline obstacles and make in-roads towards a more national voice on teaching and learning. Invited Australian educational administrator Geoff Scott (Fullan \& Scott, 2009) delivered the keynote address - chiefly to illustrate how personal and institutional change (while difficult at times) should be pursued with vigor and courage. This was followed by several round-table question-and-answer challenge sessions to identify key obstacles toward change at their respective institutions. Scott entertained the group as a whole to share their perspectives, and encouraged delegates to advance teaching and learning practices in their home institutions by utilizing a distributed leadership model.

Distributed leadership has been described as "a framework which encourages the active participation and partnering of experts and enthusiasts and the networks and communities of practices that are built to achieve organisational change" (Jones, Harvey, Lefoe, \& Ryland, 2011, p. 57). Further drawing from the work of Tagg (2003), "...part of the essential scaffolding for changing institutional structures and processes is leadership...sometimes what is needed is for persons to step up on a particular issue or problem and assume local, temporary leadership" (p.336). Scott suggested that leadership is about "motivating people... about energizing other people to make good decisions...effective leadership inspires more than it empowers; it connects more than controls; it demonstrates more than it decides" (Fullan \& Scott, 2009, p. 97). As Teaching Leadership Chairs, we have a unique opportunity to connect with colleagues on campus, to move initiatives forward, and to empower others at the grassroots level to initiate change through listening, linking, and leading. This call for 
change was at the heart of Scott's take home message for symposium delegates; individuals need to take the lead at their institutions to change the culture of teaching and learning, rather than wait for administrators to pave the way toward solutions.

Secondly, three of our seven TLCs led round-table sessions at the national conference on teaching and learning (STLHE) in Vancouver (June 2015). Through this session, we connected with participants interested in situating TLCs at their institutions, and further shared resources and experiences from the Windsor program; TLCs from neighbouring institutions further joined the discussion. For instance, Western University in London, Ontario appointed five teaching fellows in 2014, and placed a call (September 2015) for another five, with a vision of ultimately having teaching fellows in each of the faculties at Western (http://goo.gl/3KC4P2). Fellows are eligible for up to $\$ 10,000$ funding per year for three years, and receive up to $40 \%$ secondment from their departments to accomplish their educational and leadership goals. Like our TLC Council, Western TLCs regularly meet to provide useful updates, and search out solutions for issues that have arisen in their new roles. Alternatively, the University of Alberta offers six 3-year positions, plus a $\$ 20,000 /$ year stipend (https://goo.gl/DaU5o0). Other administrators may see the possibility of implementing such a program at their own institutions, with even modest funding available. Both institutional and community coffers were suggested as fruitful avenues for pursuing operational funds.

Thirdly, based on what we learned in the two previous steps, TLCs from each faculty have begun to spearhead various joint initiatives as part of the TLC Council. One such initiative is the review and revamping of our Student Evaluation of Teaching (SET) form, a similar project to what is ongoing at Queen's University and several other Ontario institutions. The importance of this initiative cannot be understated, since the impact on teaching and learning (as well as tenure and promotion) remains both vital and controversial. Plans are in place to address the issues related to our teaching evaluation form through future meetings, including another forum dedicated to teaching evaluations (see details below).

\section{Contemplating Our Future}

The university-wide initiatives on which the TLC Council collaborates are generally intended to advance teaching and learning by educating instructors and influencing teaching practice and policy. In doing so, it is hoped that student learning and the student experience will be enhanced across campus. Included below are three examples of how the TLC Council is trying to make positive changes in future teaching practices and policies at the University of Windsor.

Not unlike many institutions of higher education in Canada, the only required measures of teaching effectiveness at our institution, for purposes of renewal, tenure, and promotion (RTP), are the SET scores. It is widely accepted in the literature that students' assessments of teaching alone do not accurately reflect the teaching effectiveness of instructors (Atkinson \& Bolt, 2010; Fraile \& BoschMorell, 2015; Lomas \& Nicholls, 2005). Therefore, additional measures and factors need to be considered in the RTP process, if teaching effectiveness is to be more accurately represented on documents submitted for those purposes. Although there is some support on campus for updating the SET form and university RTP guidelines related to teaching, many instructors need to be educated about evaluation of teaching practices before changes to both the current process and university policy are broadly accepted. As one step forward, the TLC Council hosted a full day Teaching Evaluation Forum (November 2015), intended to initiate a dialogue about teaching evaluation, stimulate discussion about why changes to the current policy are needed, and provide recommendations for how teaching effectiveness should be measured, based on existing scholarly evidence. International experts (on evaluation of teaching) were invited, including Nira Hativa as a keynote speaker, and interactive sessions involving key stakeholders at all levels in the RTP process (e.g., 
instructor, Department Head, RTP committees within the academic unit and university) were planned. By organizing and supporting the Forum, the TLC Council hoped to increase the visibility of this issue and positively influence future policy changes.

Our institution recently made a historical announcement to hire 50 tenure-track faculty members at the Assistant Professor level over the next three years (http://goo.gl/m0r2ha). Interest has been considerable, given limited hiring across the higher education sector over the last several years. The workload assigned to these positions is intended to be distributed across teaching, research, and service, which is generally not supported in practice in many universities - research is widely favoured over teaching (and service), which is reflected in current hiring practices. In response to this announcement, the TLC Council discussed ways that would raise the importance of teaching throughout the hiring process. Advertisements for the first 18 jobs were posted recently (http://goo.gl/VwxYKK), and for the first time in our history, teaching dossiers and evidence of teaching effectiveness have been requested of all applicants, regardless of specialization. This simple addition has highlighted to applicants how important teaching is at our institution, and emphasized to hiring committees that they need to weight teaching significantly in the hiring process.

Many research-intensive universities undervalue teaching compared to research (Kreber, 2002; Lomas \& Nicholls, 2005; Martin \& Ramsden, 2000). In addition, there is not a universal expectation that instructors continue to develop their teaching practices over their careers. Furthermore, the expectations related to teaching competence are generally lower at the time of hiring than the expectations related to research. Whereas it is common to expect that faculty demonstrate that they have developed as a researcher (in terms of skills, impact, and reputation) in order to receive tenure and be promoted through the ranks, it is not common to expect them to do the same with respect to their teaching practices. By changing the culture related to teaching evaluation and emphasizing the importance of teaching in the hiring process, the TLC Council is optimistic that practices and policies related to the expectations of teaching development over a career will be realized in time. By hiring more effective teachers and requiring them to demonstrate that their teaching practices have developed in recent years, it is hoped that the quality and effectiveness of teaching across campus will improve in the future, thereby enhancing student learning overall.

\section{Conclusion}

In an effort to garner the same headway seen in the Canada Research Chairs Program, TLCs across the country have launched various initiatives to instill premium teaching and learning to all Canadian students in higher education. Whether as individual or joint projects, the scope and diversity of techniques and tools - grounded in theory and empirical research - offered through the implementation of Teaching Leadership Chairs, provides exciting possibilities for future growth and innovation in teaching and learning.

\section{References}

Atkinson, D. J., \& Bolt, S. (2010). Using teaching observations to reflect upon and improve teaching practice in higher education. Journal of the Scholarship of Teaching and Learning, 10(3), 1-19. Retrieved from http://josotl.indiana.edu/ index VIEW ITEM

Eansor, D. M. (2012). Teaching chairs and teaching chair programs: A report to the Vice Provost, Teaching and Learning. Windsor, ON: University of Windsor.

Fraile, R., \& Bosch-Morell, F. (2015). Considering teaching history and calculating confidence intervals in student evaluations of teaching quality. Higher Education, 70, 55-72. http://dx.doi.org/10.1007/s10734-014-982 3-0 VIEW ITEM 
Fullan, M., \& Scott, G. (2009). Turnaround leadership for higher education. San Francisco, CA: Jossey-Bass.

Jones, S., Harvey, M., Lefoe, G., \& Ryland, K. (2011). Distributed leadership: Working together to ride the waves. The Action Self Enabling Reflective Tool (ASERT). In I. Dobson, M. Conway, \& R. Shrama (Eds.), Tertiary Education Management Conference, 2011, 55-69.

Kreber, C. (2002). Teaching excellence, teaching expertise, and the scholarship of teaching. Innovative Higher Education, 27, 5-23. http://dx.doi.org/10.1023/A:10204642223 60 VIEW ITEM

Lomas, L., \& Nicholls, G. (2005). Enhancing teaching quality through peer review of teaching. Quality in Higher Education, 11, 137-149. http://dx.doi.org/10.1080/135383 20500175118 VIEW ITEM

Martin, E., \& Ramsden, P. (2000). Introduction. Higher Education Research and Development, 19, 133-135. http://dx.doi.org/10.1080/07 2943600445600 VIEW ITEM

OUSA (2011). Student Advocacy Conference/ Meeting Brief, 2011 p.1. Retrieved from http://www.ousa.ca/2011/12/07/teaching-c hairs-a-tangible-step-toward-improving-teac hing-quality-on-ontario-campuses- $\% \mathrm{E} 2 \% 8$ 0\%93-by-natalie-cockburn-december-7-201 1/ VIEW ITEM

Tagg, J. (2003). The learning paradigm college. San Francisco, CA: Anker Publishing/JosseyBass.

Wright, A., Eansor, D. M., Pugliese, T., Georgie, V., Salinitri, G., Walsh, L., Bornais, J., Lafreniere, K., \& Kustra, E. (2012). Teaching leadership chairs: A cost-efficient approach to enhancing the quality of the student learning experience at UWindsor. University of Windsor Strategic Priority Grant Application.

\section{Biographies}

David Andrews is a professor in the Faculty of Human Kinetics.

Judy Bornais is an Experiential Learning Specialist in the Faculty of Nursing.

Ken Cramer is a professor in the Department of Psychology, and a 3M National Teaching Fellow.

All three are Teaching Leadership Chairs at the University of Windsor. 


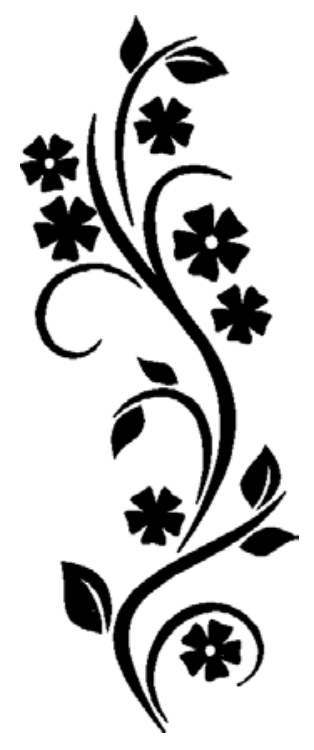

